\title{
Quantitative Damage and Fracture Mode of Sandstone under Uniaxial Load Based on Acoustic Emission
}

\author{
Ying Xu, ${ }^{1,2}$ Qiangqiang Zheng $\mathbb{D}^{1,2}{ }^{1,2}$ Xin Gao, ${ }^{1,2}$ Rongzhou Yang, ${ }^{1,2}$ Xian Ni, ${ }^{1,2}$ \\ and Qianqian Wang ${ }^{1,2}$ \\ ${ }^{1}$ State Key Laboratory of Mining Response and Disaster Prevention and Control in Deep Coal Mines, \\ Anhui University of Science and Technology, Huainan, Anhui 232001, China \\ ${ }^{2}$ School of Civil Engineering and Architecture, Anhui University of Science and Technology, Huainan, Anhui 232001, China
}

Correspondence should be addressed to Qiangqiang Zheng; qiangqz@163.com

Received 1 November 2020; Revised 4 December 2020; Accepted 9 December 2020; Published 21 December 2020

Academic Editor: Zhijie Wen

Copyright ( 92020 Ying Xu et al. This is an open access article distributed under the Creative Commons Attribution License, which permits unrestricted use, distribution, and reproduction in any medium, provided the original work is properly cited.

The damage degree and fracture mechanism of the rock are important to the bearing performance of the rock mass and the stability of the overlying structure. Most of the existing damage models for characterizing rock damage exclude the range of postpeak stress or do not consider the compaction and closure stage of the fracture, and the description of the quantitative damage of sandstone is not accurate enough. In addition, the description of the rock fracture mechanism under load is not exact enough. Aiming at the problem of quantitative damage and fracture mechanism of the loaded rock, this paper adopts acoustic emission (AE) to monitor the loading process of sandstone under uniaxial loading. In accordance with the characteristics of the AE signal, the loading stage of sandstone under uniaxial load is divided into three stages: initial hit stage, hit stability stage, and hit instability stage. By modifying the traditional damage model and combining the AE signals of the sandstone under the load, a modified damage mechanics model is obtained, which can fully express the entire loading stage. Furthermore, through the analysis of AE signals, the fracture mechanism of sandstone under uniaxial load is studied. The results show that the modified damage model can quantitatively describe the damage at different loading stages which include two areas including the fracture compaction closure stage and the postpeak stress stage. The failure and instability of sandstone under uniaxial load is mainly shear failure. The research results can provide a reference for the nondestructive testing of sandstone and engineering reliability in geotechnical engineering.

\section{Introduction}

Rock is the most common bearing medium in geotechnical engineering such as tunnels, subways, coal mines, and rock slopes [1-4]. The damage degree and fracture mechanism of the rock are critical to the stability, reliability, and personal safety of geotechnical engineering $[5,6]$. The most basic and extensive research method to study the mechanical mechanism of rocks is to analyze the mechanical characteristics of the loaded rocks. However, due to the closed and opaque nature of the rock, the damage and fracture mechanism in the sandstone under load cannot be described intuitively. Although the CT technology can intuitively study the damage and fracture mechanism of the loaded rock, due to the high cost of the experiment and the test can only be carried out in a laboratory, it is unable to monitor and analyze the loaded rock mass in a geotechnical engineering site. It is not significant to study the mechanical characteristics of sandstone in the laboratory test environment without engineering practice. In recent years, the rapid development of nondestructive testing technology has greatly promoted the monitoring of geotechnical engineering stability, and it is also one of the current research hotspots $[7,8]$. The emergence of nondestructive testing technology has played a significant role in promoting the 
monitoring of the loaded rock mass in geotechnical engineering and the stability analysis of the loaded rock mass.

When the rock is under load, its internal mesostructure evolves continuously with the increase of stress. As the stress of the rock under the load increases, the internal fissures gradually develop, expand, and penetrate, and at the same time, emit elastic waves containing rich rock mechanic characteristics that can be received by the sensor [9]. By studying the waveform signals emitted from sandstone under load, it is possible to explore the damage and fracture forms of sandstone under different stress levels. AE monitoring technology is currently one of the more commonly used methods. Many scholars have used this technology to study the mesomechanical characteristics of rocks, the law of macrofailure, and the identification of critical failure precursors [10-12]. Some scholars have also used numerical simulation to analyze the damage laws and failure characteristics of rocks during loading. These research results provide a reference for the safe production of engineering.

Many scholars have achieved fruitful results in the research on the damage and fracture mechanism of the loaded rock and successfully guided the safe production of many geotechnical engineering. On the basis of the mesostructure of the rock, $\mathrm{Li}$ et al. [13] used a discrete element model to analyze the mechanical behavior of sandstone under load and verified it with mechanical tests. Based on different confining pressure conditions, Wang et al. [14] carried out cyclic loading and unloading tests on sandstone, established an isotropic sandstone damage evolution model considering plastic coupling, and verified it through numerical simulation. Weng and Li [15] discussed the influence of porosity and particle area ratio on the elastoplastic deformation of sandstone and used a modified bonded particle model to study the deformation behavior of sandstone under bidirectional loading. Cao et al. [16] connected the improved the Burgers model, Hooke model, and St. Venant model in series to define a new nonlinear damage constitutive model for high-stress soft rock and verified it with the monitoring results of a geotechnical engineering site. Combining the basic theory of continuum damage mechanics, Mortazavi and Molladavoodi [17] established a more accurate damage function of the loaded rock and used field tests to verify the newly developed damage model. Zhang et al. [18] considered the rock deformation and strength degradation caused by damage in the elastic stiffness matrix and plastic yield criterion, constructed an elastoplastic damage coupling model for brittleness demonstration, and established a damage criterion to judge whether the rock was damaged. The construction of rock damage mechanics models under these loads has greatly promoted the guidance of engineering safety production. But, as far as the scope of application is concerned, these mechanical models have certain limitations, and most of them rely on other factors such as engineering environment, temperature, or lithology.
In terms of the rock damage mechanism, since Tang and $\mathrm{Xu}$ [19] and Xie [20] introduced the Weibull distribution to characterize the rock damage mechanics model, which is shown in equation (1), many scholars [21-23] established rock damage models based on it, which is shown in equation (2). But, there are some errors in these models; for equation (2), the damage is calculated from another point instead of the original point, and the microdamage caused by the closed and expanded cracks in the specimen is ignored. Moreover, this error does not appear in equation (1), but it does not consider the damage after the peak stress. For the damage after the peak stress, its value is the same as before the peak stress and smaller than the damage value at the peak stress, which is contrary to reality:

$$
\begin{aligned}
& P(\sigma)=1-e^{-(\sigma / \lambda)^{\alpha},} \\
& P(\sigma)= \begin{cases}1-e^{-\left(\sigma-\sigma_{0} / \lambda\right)^{\alpha}}, & \sigma \geq \sigma_{0}, \\
0, & \sigma<\sigma_{0},\end{cases}
\end{aligned}
$$

where $\sigma_{0}$ is the stress at the beginning of the calculation of damage, $\sigma$ is the axial stress of the rock, and $\alpha$ and $\lambda$ are the parameters related to the rock.

In summary, the damage and fracture mechanism of sandstone under load is mostly based on changes in engineering environment, lithology, and temperature. However, there are few studies on the damage and failure mechanism of rocks including the postpeak stress part, and there is no reasonable mechanical model. Based on the aforementioned research results, there is an urgent need to find a damage model with a simple form, fewer parameters, and including the before and after peak stress.

In this paper, the AE monitoring method is adopted to collect the AE signals emitted in the sandstone under uniaxial load, divide the loading process of the sandstone according to the law of the AE signals, and combine the damage mechanics model to quantitatively analyze the damage of the loaded sandstone. Moreover, the fracture mechanism of sandstone under load is studied by analyzing the AE signals.

\section{Model Construction}

The damage mechanics model constructed by many scholars is widely used in the field of geotechnical engineering, among which the most widely used are equations (1) and (2). In Section 1, the advantages and disadvantages of these mechanical models are analyzed. In order to make it reasonable to explain the damage of the loaded sandstone including postpeak stress, combined with the AE device, the $\mathrm{AE}$ hit ratio (HR) is defined, as shown in equation (3). At the same time, in order to satisfy that the modified damage mechanics model can describe the entire process of the loaded rock, the function value corresponding to the postpeak stress should be larger than the function value before the peak stress and is a monotonically increasing function. Defininge function $f\left(\sigma_{t}\right)$ as shown in equation (4): 


$$
\begin{aligned}
\mathrm{HR} & =\frac{N_{t}}{N_{0}}, \\
f\left(\sigma_{t}\right) & = \begin{cases}\left(0.5 \sigma_{t} / \sigma_{b}\right), & \left(\varepsilon_{t} \leq \varepsilon_{0}\right), \\
1-\left(0.5 \sigma_{t} / \sigma_{b}\right), & \left(\varepsilon_{t}>\varepsilon_{0}\right),\end{cases}
\end{aligned}
$$

where $N_{t}$ represents the cumulative hit count of AE events generated inside the loaded sandstone from 0 to $t, N_{0}$ represents the cumulative hit count of $\mathrm{AE}$ events until the sandstone is completely destroyed (the end of the test), $\sigma_{t}$ represents the stress value of the loaded sandstone at time $t$, and $\sigma_{b}$ represents the peak stress of the sandstone.

Bringing the defined function $f\left(\sigma_{t}\right)$ into equation (2) first, as shown in the following equation:

$$
P\left(f\left(\sigma_{t}\right)\right)= \begin{cases}1-e^{-\left(\left(f\left(\sigma_{t}\right)-f\left(\sigma_{0}\right)\right) / \lambda\right)^{\alpha}}, & \sigma \geq \sigma_{0} . \\ 0, & \sigma<\sigma_{0} .\end{cases}
$$

Regarding equation (5) as a mathematical function, the rationality of the function is analyzed from a theoretical perspective. On the basis of satisfying the rationality of the mathematical meaning of the function, the mechanics mechanism is discussed. The value range of the function is $[0,1]$. When its definition range is extended to $\sigma<\sigma_{0}$, the value range will be less than 0 , which is contrary to the mechanical mechanism of loaded sandstone. Therefore, the equation needs to be corrected. After the correction, the value range of the function is $(0,1)$, and the domain can satisfy the entire set of real numbers. In order to facilitate the calculation, replace $f\left(\sigma_{0}\right)$ with $x_{0}$, take the value of $\alpha$ as 1 , and multiply it by the correction coefficient $\eta$. AE cumulative hit count HR can indicate the degree of damage inside the specimen [12], so HR can be used to indicate the degree of damage to the loaded sandstone. Equation (5) can be simplified as shown in equation (6), which can satisfy the abovementioned model expression and solve the existing drawbacks:

$$
\mathrm{HR}=P\left(f\left(\sigma_{t}\right)\right)=1-\frac{\eta}{1+\exp \left(\left(f\left(\sigma_{t}\right)-x_{0}\right) / \lambda\right)},
$$

where $x_{0}$ and $\lambda$ are the parameters related to rocks.

Equation (6) effectively connects the AE parameters with the damage degree of the loaded sandstone, expounds the failure mechanism reasonably, and quantifies the damage degree. It has a simple form, few parameters, and includes two stages before and after the peak stress.

\section{Experiment}

The rock specimens used in this test were taken from the main roadway roof of a coal mine in Huainan City, Anhui Province, using in situ sampling. After the taken-out rock sample is processed indoors, it is prepared into a standard cylindrical specimen with a size of $50 \mathrm{~mm} \times 100 \mathrm{~mm}$ (diameter $\times$ height). In order to reduce the experimental error caused by the processing of the test piece, it is also necessary to ensure that the flatness tolerance of the bearing surface of each sandstone test piece after grinding is less than $0.02 \mathrm{~mm}$, the axis of the sandstone test piece is perpendicular to the end surface, and the deviation does not exceed $0.001 \mathrm{rad}$. The prepared test pieces are numbered, respectively, which are S-1, S-2, S-3, S-4, and S-5 in sequence.

This experiment adopts two test systems, namely, the rock mechanics test system of SANSI technology and the DS5 series full-information AE signal analyzer of Beijing Soft Island Technology (as shown in Figures 1 and 2, respectively). The rock mechanics test system can record and store the changes in the stress and strain of the specimen with time in real-time. The AE monitoring system can track, record, and store various parameters of $\mathrm{AE}$ events and the location of the sound source in real-time. The uniaxial loading test and the $\mathrm{AE}$ monitoring test are carried out simultaneously, and the press applied a load to the sandstone with an axial loading rate of $1.2 \mathrm{~mm} / \mathrm{min}$. Each sandstone specimen adopts 8 sensor probes to collect the AE signals of the loaded sandstone to realize real-time monitoring and three-dimensional positioning of the $\mathrm{AE}$ signal. The $\mathrm{AE}$ signal amplifier is set to $40 \mathrm{~dB}$, the threshold of each channel is set to $100 \mathrm{mV}$, and the sampling frequency is $3 \mathrm{MHz}$. The $\mathrm{AE}$ monitoring system processes and stores the signals monitored by the eight sensors and obtains the waveform parameters of the sandstone under uniaxial load and the red AE source location mark. The location of the sensor probe is shown in Figure 3. In order to enhance the AE monitoring effect, petroleum jelly is evenly applied on the signal acquisition surface of the sensor probe and stuck on the predesigned monitoring point. Before the start of the test, a pretest is carried out with the pencil lead as the analog source to detect its response to the signal source. At the same time, the interference of external impact, friction, and other mechanical noise is eliminated, and the test is started after the debugging is normal.

\section{Experimental Results and Analysis}

4.1. Strength. According to the test results, the uniaxial compressive strength of the 5 sandstones is sorted out as shown in Table 1. Obtaining the average compressive strength of sandstone under uniaxial load, the specimen with the smallest absolute difference from the average value for analysis is selected based on the obtained average compressive strength.

According to the strength results of sandstone, the average strength of sandstone under uniaxial load is 60.21 MPa. The strength of the rock under load is the most basic parameter to study the reliability and stability of the rock mass, but its damage degree and fracture mechanism under different stress levels are also important. By analyzing the damage and fracture modes of the loaded sandstone under different stress levels, it can give a certain reference to the disaster prevention of the rock mass.

4.2. Quantitative Damage Analysis. Analyzing the AE signals of the sandstone under the load, the relationship between time-stress-AE energy-accumulated number of hits of the loaded sandstone is obtained, as shown in Figure 4. Taking time as the independent variable and stress, AE energy, and 


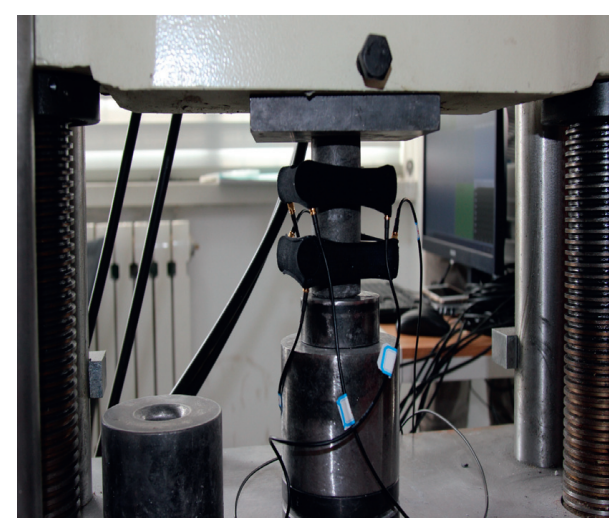

FIgURE 1: Rock loading device.

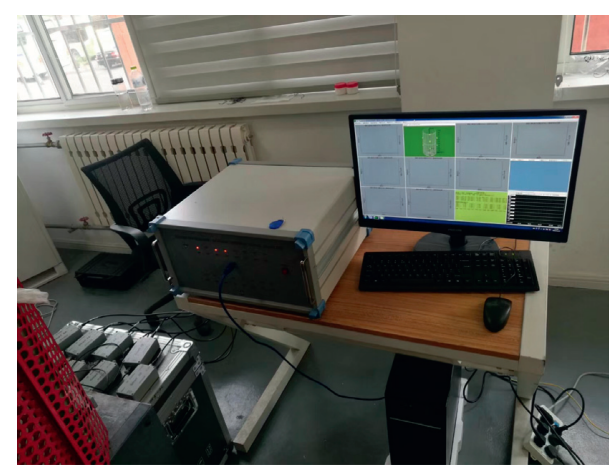

FIgURE 2: AE collection device.

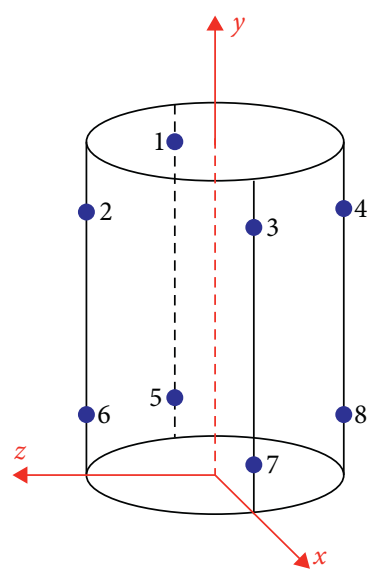

FIgURE 3: Layout of the AE sensor probe.

TABle 1: Test result statistics.

\begin{tabular}{lc}
\hline Number & Strength $(\mathrm{MPa})$ \\
\hline S-1 & 57.89 \\
S-2 & 62.76 \\
S-3 & 59.55 \\
S-4 & 63.93 \\
S-5 & 56.92 \\
$\bar{x}$ & 60.21 \\
\hline
\end{tabular}

cumulative hit count as the dependent variables, the four parameters of AE obtained by monitoring are comprehensively analyzed.

It can be seen from the graphical results that the stress gradually increases with the passage of time, and the $\mathrm{cu}-$ mulative hit count of the $\mathrm{AE}$ of the loaded sandstone also increases monotonously. According to the change law of AE signals, the loading process of sandstone under load is divided into three stages: initial hit stage, hit stability stage, and hit instability stage. In the initial hit stage, the curve of the cumulative number of AE hits of the loaded sandstone rises rapidly in a short time and then reaches the hit stability stage, during which the growth rate slows down and is excessively slow. When the hit instability stage is reached, the cumulative hit count of $\mathrm{AE}$ increases rapidly until the sandstone is completely destroyed.

Some research results show that the cumulative hit count of the AE of the loaded rock can be used to characterize its damage $[12,24]$. The difference $\Delta \mathrm{HR}$ of the accumulative AE hit count of the loaded sandstone is distinct in different stress ranges. $\triangle \mathrm{HR}$ represents the difference between the maximum value and the minimum value of $H R$ in the stage and reflects the ratio of the cumulative hit count of $\mathrm{AE}$ to the cumulative hit count of the specimen in this stage. Among the three stages of sandstone under uniaxial load, the $\Delta H R$ in the hit instability stage is the largest and the smallest in the initial hit stage. The magnitude of the AE energy is also different in distinct loading stages of sandstone, the smallest in the initial hit stage and the largest in the last stage.

The difference of the AE signals of the loaded sandstone under different stress levels is closely related to its mechanical characteristics. The rock under the load has experienced the crack compaction closure stage, elastic stage, plastic stage, and failure and instability stage [25]. Among them, the initial hit stage and hit stability stage of the AE signals correspond to the fracture compaction closure phase and the elastic phase of the loaded sandstone, respectively. The hit instability stage includes the plastic deformation stage and the failure instability stage. There are natural primary pores in the rock. Under low stress levels, the primary pores randomly distributed in the rock are compacted and closed and trigger the AE signals [26]. Due to the large number of primary pores in the rock, there are more $\mathrm{AE}$ events, and the cumulative hit count is also larger, but the size is smaller than crack propagation. Therefore, the $\mathrm{AE}$ energy is the lowest among the three stages. In addition, it can be seen from the graphical results that although the energy amplitude within this stage is generally small, there are still a small number of AE events with large energy amplitudes. This is due to the different sizes of natural primary pores in sandstone. Under the action of load, pores or subdefects with larger sizes will be compacted and closed and emit AE events. Compared with the smaller pores in the loaded sandstone being compacted and closed, the energy of the $\mathrm{AE}$ event emitted by the larger pores being compacted and closed is larger.

As the load continues to increase, the rock enters the elastic deformation stage, at which time the solid mineral particles in the rock play a major bearing role. Under the 


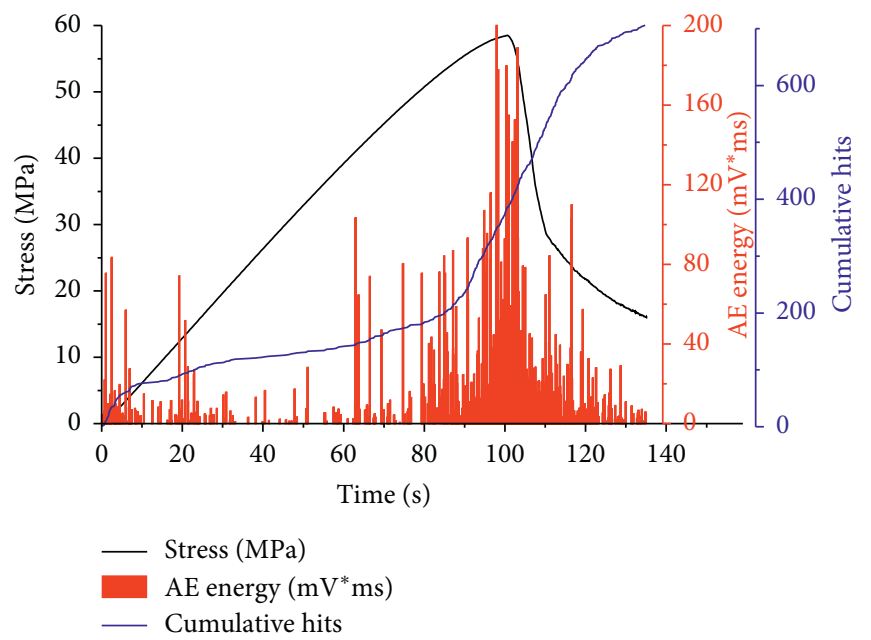

Figure 4: AE signal characteristic curve of sandstone.

action of external force, the solid mineral particles in the rock begin to deform, but this deformation can be restored when the external force is removed. Therefore, there are fewer $\mathrm{AE}$ events in the loaded sandstone in this case. However, due to the randomness of the solid mineral particles in the rock, the edges and corners of some solid mineral particles are small. Under the action of the load, due to the tip effect of the crack, the transition surface between this part of the solid mineral particles and the cemented matrix first begins to crack and emits $\mathrm{AE}$ events. But, at the same time, the cemented matrix in the rock has not cracked, only the transition surface between some irregular solid mineral particles and the cemented matrix cracked, and the number of such cases in this stage is relatively small. Therefore, the AE energy is larger than the initial hit stage, but the cumulative hit count increases the least.

With the increase of load, the transition surface of the crack gradually expands under the influence of the crack tip effect, the cracks in the cemented matrix also begin to expand, and the rock enters the hit instability stage, namely, the plastic deformation stage and the failure instability stage [27]. The crack propagation accompanied by the cracking of the cemented matrix induces secondary cracks. With the action of external force, the cracks increase exponentially and gradually penetrate to form the main cracks until they are completely destroyed [28]. The scale and range of cracks in this stage are much larger than those in the previous two stages. Therefore, the increase in the AE energy and the cumulative hit count are both maximized. Within this stage, it can be seen that when the stress is in the area before the peak stress, the $\mathrm{AE}$ events are denser, and the energy is also larger, reaching the highest value among the three stages. When the stress is in the postpeak stress region, the main crack in the rock at this time has penetrated, but the damage rock can still bear the load. The AE sensors are still tightly coupled with the rock. At this time, the collected AE signals are still large, and the energy is also large, but it is lower than the energy at the peak stress. With the passage of time, the rock has completely lost the ability to resist deformation. At this time, the energy of the AE event inside the loaded sandstone is smaller, and the frequency of emitting the $\mathrm{AE}$ event is also lower than the area before the peak stress.

In order to intuitively analyze the damage degree of the loaded sandstone and quantitatively analyze the damage value of the loaded sandstone under different stress levels, with the time parameter as the intermediate variable, the stress of each $\mathrm{AE}$ event emitted in the loaded sandstone is associated with the cumulative AE hit count. Then, putting the stress into equation (4), the obtained function value is taken as the abscissa, HR is taken as the ordinate, and the constructed scatter diagram is shown in Figure 5.

In the theoretical analysis part, the relationship between HR and stress is analyzed, as shown in equation (6). In order to verify whether equation (6) can reasonably describe the damage of the loaded sandstone under different stress levels and quantitatively describe the damage value, the scatter diagram of Figure 5 is fitted with equation (6). However, if it is directly fitted, it will be found that both the Weibull distribution model and equation (6) ignore the initial hit stage, and the $\Delta H R$ value of the loaded sandstone at this stage is $8 \%$, which cannot be ignored directly, and a segmented analysis is required. In the original Weibull distribution model, the 1 before the minus sign is related to the range of the distribution function. Therefore, after fitting the first part of the piecewise function (the initial hit stage), the 1 before the minus sign is changed to the $\Delta \mathrm{HR}$ value of the loaded sandstone during the initial hit stage. Due to the influence of the initial hit stage, the 1 before the minus sign in the second part (hit stability stage and hit instability stage) should be added to the first-stage $\Delta \mathrm{HR}$ value. Taking the end point of the first part as the starting point of the second part is also a necessary condition to ensure that the range of the piecewise composite function does not repeat. Equation (6) is further modified, and the modified damage mechanics model is shown in the following equation: 


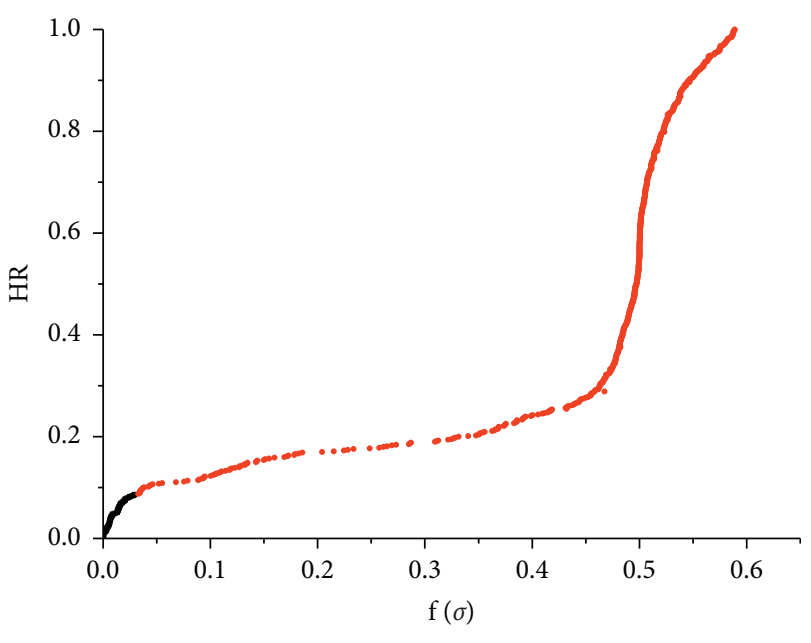

- HR of part 1

- HR of part 2

FIGURE 5: Scatter plot for constructing functions.

$$
\mathrm{HR}=P\left(f\left(\sigma_{t}\right)\right)=a-\frac{\eta}{1+\exp \left(\left(f\left(\sigma_{t}\right)-x_{0}\right) / \lambda\right)} .
$$

Using the modified damage mechanics model to perform segmental fitting analysis on the data in Figure 5, as shown in Figure 6. It can be seen that after fitting, the goodness of fitting between the stress of the loaded sandstone and the HR is higher. This shows that the revised damage mechanics model is more reliable and can be used as a basis for quantitatively elaborating the damage degree of the loaded sandstone.

Performing function processing on the modified damage mechanics model and recording it as the function $h(x)$. Using mathematical analysis to analyze the function theoretically. After obtaining the derivative, as shown in equation (8), its first derivative is always greater than 0 , that is, the function $h(x)$ is a monotonically increasing function. Since equation (4) is also monotonically increasing, the composite function of the two is also a monotonically increasing function, that is, the hit ratio is monotonously increasing, which is consistent with the experimental results. The second derivative of $h(x)$ represents the inflection point of the function curve at $x=x_{0}$, that is, the hit ratio growth rate gradually increases before the point $x_{0}$, and the hit ratio growth rate gradually decreases after $x_{0}$. It can be seen from Figure 6 that the inflection point of the function is within the range of the hit instability stage. Because the hit rate is relatively stable during the impact stabilization stage, the cracks in the loaded sandstone penetrated and expanded rapidly in the early stage of the hit instability stage, and the rate of hit rate increased gradually until the main crack penetrated. After that, the hit rate still increased, but the growth rate of the hit rate is slower than that before $x_{0}$. The main reason is that after the main crack penetrates, the secondary cracks propagate slowly, which is consistent with the postpeak stress-strain curve view of the loaded sandstone. For the initial hit stage, there are more primary pores in the loaded sandstone, and the growth rate of the hit ratio is larger. When the primary pores are closed to a certain extent, the stress concentration phenomenon slows down, and the growth rate of the hit ratio decreases, but the hit ratio still gradually increases:

$$
\begin{aligned}
h^{\prime}(x) & =\frac{\eta \times \exp \left(x-x_{0} / \lambda\right)}{\lambda\left(1+\exp \left(\left(x-x_{0} / \lambda\right)\right)\right)^{2}}, \\
h^{\prime \prime}(x) & =\frac{\eta \times \exp \left(x-x_{0} / \lambda\right)\left(1-\exp \left(x-x_{0} / \lambda\right)\right)}{\lambda^{2}\left(1+\exp \left(x-x_{0} / \lambda\right)\right)^{3}} .
\end{aligned}
$$

Combining the mechanical properties of the loaded sandstone and mathematically analyzing the theoretical significance of the damage function. The modified damage mechanics model is shown in the following equation:

$$
H R=P\left(f\left(\sigma_{t}\right)\right)= \begin{cases}0.1-\frac{0.1}{1+\exp \left(\left(f\left(\sigma_{t}\right)-0.012\right) / \lambda\right)}, & f\left(\sigma_{t}\right)<0.04 \\ 1.1-\frac{1}{1+\exp \left(\left(f\left(\sigma_{t}\right)-0.012\right) / \lambda\right)}, & f\left(\sigma_{t}\right) \geq 0.04\end{cases}
$$

4.3. Fracture Mechanism. The sandstone under load and the wave signal emitted inside contain rich rock mechanic characteristics including the rock fracture mechanism. By analyzing the cumulative hit count and energy in the $\mathrm{AE}$ signals, the damage degree of the loaded sandstone is quantitatively analyzed under different stress levels. However, the failure mechanism of the rock has not been analyzed in detail. The rising angle (RA) and average frequency $(\mathrm{AF})$ in the AE parameters are closely related to the rock fracture mechanism [29]. Analyzing the parameters such as rise time, amplitude, ringing count, and duration in the $\mathrm{AE}$ signals of the sandstone specimen, the fracture mode of the loaded sandstone can be grasped. The existing research results show that the relative relationship between the value of the AE parameter RA (angle of rise) and the value of AF (average frequency) can be used to distinguish the failure modes of brittle building materials such as rocks, as shown in equations (11) and (12), respectively, [30, 31]: 


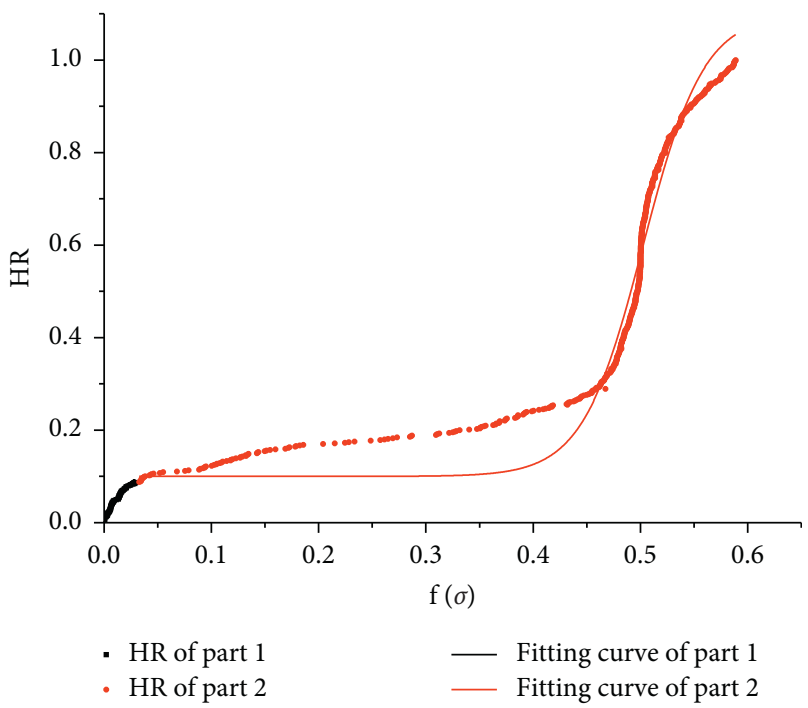

FIGURE 6: Fitting curve of the modified damage mechanics' model.

$$
\begin{aligned}
& \mathrm{RA}=\frac{\text { rise time }}{\text { amplitude }} \\
& \mathrm{AF}=\frac{\text { ringing count }}{\text { time interval }} .
\end{aligned}
$$

In the formula, the rise time is the time interval from the first time that the AE event signal crosses the threshold to the maximum amplitude value, $\mu$ s. The waveform amplitude is the maximum amplitude value of the AE event signal, $\mathrm{dB}$. The ringing count is the number of oscillations that cross the threshold signal, which can be divided into total count and count rate. The duration is the time interval from the first time that the AE event signal crosses the threshold to the final threshold, $\mu$ s.

The fracture of the rock under load is mainly divided into tension failure and shear failure. Different fracture modes have different internal wave signals. When the fracture point in the loaded rock undergoes shear failure, the elastic waves emitted by the AE event mainly propagate in the form of transverse waves and are received by the sensors. The frequency and speed of the transverse waves are relatively small. When tensile failure occurs at the rupture point, the elastic waves emitted by the AE event mainly propagate in the form of longitudinal waves and are received by the sensors. The amplitude and frequency of this waveform are higher, and the propagation speed is faster, so the rise time is shorter. Therefore, when the value of RA is low and the value of $\mathrm{AF}$ is high, the failure mode of the rock is tensile failure; on the contrary, the failure mode of the rock is shear failure, as shown in Figure 7.

The sandstone under uniaxial load emits many AE events. The failure mechanism of the rock where each $\mathrm{AE}$ event is emitted is different, including shear failure and tensile failure. However, it is possible to analyze the number of two types of fracture points in the loaded sandstone to explore the fracture mechanism of the sandstone. The number of rupture points obtained by the AE monitoring of the five sandstone specimens is statistically analyzed. In

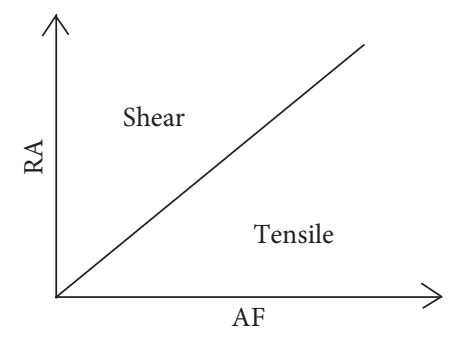

FIGURE 7: Classification basis of sandstone failure forms under load.

Table 2: Proportion of different types of AE events.

\begin{tabular}{lccccc}
\hline & S-1 (\%) & S-2 (\%) & S-3 (\%) & S-4 (\%) & S-5 (\%) \\
\hline Shear & 67 & 71 & 56 & 77 & 62 \\
Tensile & 33 & 29 & 44 & 23 & 38 \\
\hline
\end{tabular}

order to eliminate the influence of the number of AE events, the statistics are calculated as a percentage, as shown in Table 2.

Analyzing the percentage of AE event types of five sandstones, it can be seen that the damage of sandstone under uniaxial load is mainly shear failure. This is because under uniaxial load, the confining pressure is lost, and the cracks in the sandstone gradually expand and connect. As the load increases, the main crack gradually penetrates and forms an angle of approximately $45^{\circ}$ with the axial direction of the sandstone. The sandstone on both sides of the main crack gradually slips under the action of the load, and the specimen is finally sheared.

\section{Discussion and Conclusion}

The mechanism of rock damage and fracture mechanism under uniaxial load is the most basic and mature method for studying rock mechanic characteristics. Some scholars combine new equipment and new technology to explore rock damage, but they all build rock constitutive models. To characterize the degree of damage, the description of the postpeak stress area does not match the actual engineering. When applied to actual engineering, corresponding adjustments need to be made for different engineering environments. As a research technique, its scope of application is relatively limited. Although this article adopts a common test system for AE monitoring of loaded rock under uniaxial load, it also describes the damage of loaded sandstone under different stress levels based on theoretical analysis. It can quantitatively analyze the damage of sandstone, so that it can predict the damage of rock in engineering. New methods have been developed for predicting the damage and destruction of rock masses. In addition, the monitored $\mathrm{AE}$ signals are combined to analyze the failure mechanism of sandstone under uniaxial load. Although most rocks in geotechnical engineering are under confining pressure, the study of the fracture mechanism of sandstone under uniaxial load can provide technical support for the study of the sandstone fracture mechanism under confining pressure. 
In this paper, the theoretical analysis method is used to analyze the damage model of the loaded rock, combined with the characteristics of rock mechanics, and according to the loading state of the sandstone in the actual project, the traditional damage mechanics model is revised. Then, the $\mathrm{AE}$ is used to monitor the entire loading process of the sandstone under uniaxial load, and the monitored AE signals are analyzed. Through the analysis of AE signal characteristics, the loading process of sandstone is divided into three stages: initial hit stage, hit stability stage, and hit instability stage. Finally, the mechanical model constructed is fitted to the waveform signals monitored by AE. From the results of the fitting, it can be known that the modified damage mechanics model can reasonably describe the damage degree of the loaded sandstone under different stress levels and can quantitatively describe the damage of the sandstone.

\section{Data Availability}

The data used to support the findings of this study are included within the article.

\section{Conflicts of Interest}

The authors declare that they have no conflicts of interest.

\section{Acknowledgments}

This work was funded by the National Natural Science Foundation of China (no. 52074009) and the Natural Science Foundation of Anhui Province (no. 1908085QE184).

\section{References}

[1] G. Zhang, L. Chen, Z. Wen et al., "Squeezing failure behavior of roof-coal masses in a gob-side entry driven under unstable overlying strata," Energy Science \& Engineering, vol. 8, no. 7, pp. 2443-2456, 2020.

[2] G. Zhang, S. Liang, Y. Tan, F. Xie, S. Chen, and H. Jia, "Numerical modeling for longwall pillar design: a case study from a typical longwall panel in China," Journal of Geophysics and Engineering, vol. 15, no. 1, pp. 121-134, 2018.

[3] M. C. He, J. L. Miao, and J. L. Feng, "Rock burst process of limestone and its acoustic emission characteristics under truetriaxial unloading conditions," International Journal of Rock Mechanics and Mining Sciences, vol. 47, no. 2, pp. 286-298, 2010.

[4] X. Li, Z. Li, E. Wang et al., "Pattern recognition of mine microseismic (MS) and blasting events based on wave fractal features," Fractals, vol. 26, no. 3, Article ID 1850029, 2018.

[5] V. A. Akinbinu, "Multivariate analysis of fracture toughness, brittleness and blasting geometric ratios for the prediction of fragmentation output," International Journal of Rock Mechanics and Mining Sciences, vol. 93, pp. 324-329, 2017.

[6] Z. J. Wen, X. Wang, Y. L. Tan, H. L. Zhang, W. P. Huang, and Q. H. Li, "A study of rockburst hazard evaluation method in coal mine," Shock and Vibration, vol. 2016, Article ID 8740868, 9 pages, 2016.

[7] G. Gauthier and A. L. Burke, "The effects of surface weathering on the geochemical analysis of archaeological lithic samples using non-destructive polarized energy dispersive XRF," Geoarchaeology, vol. 26, no. 2, pp. 269-291, 2011.

[8] Z. T. Karpyn, P. M. Halleck, and A. S. Grader, "An experimental study of spontaneous imbibition in fractured sandstone with contrasting sedimentary layers," Journal of Petroleum Science and Engineering, vol. 67, no. 1-2, pp. 48-56, 2009.

[9] C. Zhang, W. Liang, Z. Li, S. Xu, and Y. Zhao, “Observations of acoustic emission of three salt rocks under uniaxial compression," International Journal of Rock Mechanics and Mining Sciences, vol. 77, pp. 19-26, 2015.

[10] J. Wu, M. Feng, B. Yu, W. Zhang, X. Ni, and G. Han, "Experimental investigation on dilatancy behavior of water-saturated sandstone," International Journal of Mining Science and Technology, vol. 28, no. 2, pp. 323-329, 2018.

[11] A. Yuan, P. Wang, and L. Yang, "Movement laws of overlying strata and prevention measures of dynamic disasters under deep adjacent coal seam group with high gas," Geomatics Natural Hazards and Risk, vol. 11, no. 1, pp. 2339-2359, 2020.

[12] Q. Zheng, Y. Cheng, Q. Zong, Y. Xu, F. Li, and P. Chen, "Failure mechanism of different types of shotcrete based on modified Weibull distribution model," Construction and Building Materials, vol. 224, pp. 306-316, 2019.

[13] L. Li, I. Larsen, and R. M. Holt, "Laboratory observation and micromechanics-based modelling of sandstone on different scales," Rock Mechanics and Rock Engineering, vol. 48, no. 4, pp. 1407-1422, 2015.

[14] S. S. Wang, W. Y. Xu, W. Wang, and C. J. Jia, "Experimental and numerical investigations on the mechanical behavior of fine-grained sandstone," International Journal of Geomechanics, vol. 18, no. 2, Article ID 04017150, 2018.

[15] M.-C. Weng and H.-H. Li, "Relationship between the deformation characteristics and microscopic properties of sandstone explored by the bonded-particle model," International Journal of Rock Mechanics and Mining Sciences, vol. 56, pp. 34-43, 2012.

[16] C. Ping, Y. D. Wen, Y. X. Wang, H. P. Yuan, and B. X. Yuan, "Study on nonlinear damage creep constitutive model for high-stress soft rock," Environmental Earth Sciences, vol. 75, no. 10, Article ID 900, 2016.

[17] H. Molladavoodi and A. Mortazavi, "A damage-based numerical analysis of brittle rocks failure mechanism," Finite Elements in Analysis and Design, vol. 47, no. 9, pp. 991-1003, 2011.

[18] J. C. Zhang, W. Y. Xu, H. L. Wang, R. B. Wang, Q. X. Meng, and S. W. Du, "A coupled elastoplastic damage model for brittle rocks and its application in modelling underground excavation," International Journal of Rock Mechanics and Mining Sciences, vol. 84, pp. 130-141, 2016.

[19] C. A. Tang and X. H. Xu, "Evolution and propagation of material defects and Kaiser effect function," Journal of Seismology Research, vol. 13, no. 2, pp. 203-213, 1990, in Chinese.

[20] H. XIE, Damage Mechanics of Rock and Concrete, China University of Mining and Technology Press, Beijing, China, 1990, in Chinese.

[21] J. W. Zhou, W. Y. Xu, and X. G. Yang, "A microcrack damage model for brittle rocks under uniaxial compression," Mechanics Research Communications, vol. 37, no. 4, pp. 399-405, 2010.

[22] L. Olsen-Kettle, "Using ultrasonic investigations to develop anisotropic damage models for initially transverse isotropic materials undergoing damage to remain transverse isotropic," International Journal of Solids and Structures, vol. 138, pp. 155-165, 2018. 
[23] A. Shojaei, A. Dahi Taleghani, and G. Li, "A continuum damage failure model for hydraulic fracturing of porous rocks," International Journal of Plasticity, vol. 59, pp. 199-212, 2014.

[24] J. Zhang, W. Peng, F. Liu, H. Zhang, and Z. Li, "Monitoring rock failure processes using the hilbert-huang transform of acoustic emission signals," Rock Mechanics and Rock Engineering, vol. 49, no. 2, pp. 427-442, 2016.

[25] F. Davood, "Determination of the geotechnical characteristics of hornfelsic rocks with a particular emphasis on the correlation between physical and mechanical properties," Rock Mechanics and Rock Engineering, vol. 49, no. 7, pp. 2595$2608,2016$.

[26] G. N. Khan, "Effect of the combination characteristics of rock structural plane on the stability of a rock-mass slope," Bulletin of Engineering Geology and the Environment, vol. 73, no. 4, pp. 987-995, 2014.

[27] G. Manthei, "Application of the cluster analysis and time statistic of acoustic emission events from tensile test of a cylindrical rock salt specimen," Engineering Fracture Mechanics, vol. 210, pp. 84-94, 2019.

[28] S. Duca, C. Occhiena, and L. Sambuelli, "A procedure to determine the optimal sensor positions for locating $\mathrm{AE}$ sources in rock samples," Rock Mechanics and Rock Engineering, vol. 48, no. 2, pp. 481-493, 2015.

[29] A. Juneja and M. Endait, "Laboratory measurement of elastic waves in Basalt rock," Measurement, vol. 103, pp. 217-226, 2017.

[30] M. R. M. Aliha and M. R. Ayatollahi, "Rock fracture toughness study using cracked chevron notched Brazilian disc specimen under pure modes I and II loading-a statistical approach," Theoretical and Applied Fracture Mechanics, vol. 69, pp. 1725, 2014.

[31] F. Finck, M. Yamanouchi, H.-W. Reinhardt, and C. U. Grosse, "Evaluation of mode I failure of concrete in a splitting test using acoustic emission technique," International Journal of Fracture, vol. 124, no. 3-4, pp. 139-152, 2003. 